\title{
Çok Sayıda Trikobezoar
}

\author{
Multiple Trichobezoars
}

Müslim Yurtçu

Necmettin Erbakan Üniversitesi Meram Tıp Fakültesi Çocuk Cerrahi Anabilim Dalı, Konya, Türkiye

Geliş Tarihi/Received: 4 Ekim 2018

Kabul Tarihi/Accepted: 11 Ocak 2019

Yazıșma Adresi: Müslim Yurtçu, Necmettin Erbakan Üniversitesi Meram Tıp Fakültesi Çocuk Cerrahi Anabilim Dalı, Konya, Türkiye E-posta: myurtcu@erbakan.edu.tr

\section{ORCID}

Müslim Yurtçu

https://orcid.org/0000-0002-5783-7181

\section{Öz}

Bezoarlar, lifli ya da emilemeyen gıdaların sindirim sisteminde sürekli birikimi sonucu ortaya çıkarak belli bir yer işgal eden katılaşmıs cisimlerdir. Çocuklardaki bezoarların çoğu; oyuncak bebek ya da fırçalardaki saçların yutulması ile oluşurlar. Trikobezoarlar, tipik olarak karın ağrısı ve bulantıya sebep olurlar; aynı zamanda asemptomatik abdominal kitleden, barsak tıkanıklığı ve barsak perforasyonuna kadar giden belirtilerle seyrederler. Trikobezoarlar, daha çok duygusal olarak rahatsız olan ya da mental retarde çocuklarda görülür. 8 yaşındaki bir kız çocuğunda seyrek görülen dev bir trikobezoarı sunulmaktadır. Söz konusu trikobezoar, oldukça büyük ve duodenuma geçtiğinden dolayı endoskopik olarak çıkarılamadı. Keza, yumuşatıcılar ve papain enzimi de etkili olmadı. Cerrahi olarak supraumblikal median kesi ile karın açılarak eksplorasyon yapıldı. Yaklaşık $15 \times 3 \mathrm{~cm}$ ebadındaki trikobezoar, ileoçekal segmentin $50 \mathrm{~cm}$ proksimalinde tespit edildi ve çıkarıldı; $10 \mathrm{~cm}$ 'lik jejunal segment Heineke Mikulicz prosedürü ile onarıldı.

Anahtar Kelimeler: Trikobezoar, karında kitle, ileus, rapunzel sendromu.

\section{Abstract}

Bezoars are concretions in the gastrointestinal tract that increase in size by continuous accumulation of non-absorbable food or fibers. Most bezoars in children are trichobezoars from swallowed hair from the dolls or brushers. Trichobezoars typically cause abdominal pain and nausia, but can also present as an asymptomatic abdominal mass, progressing to intestinal obstruction and perforation. It is predominantly found in emotionally disturbed or mentally retarded youngers. We report a case of an unusual giant trichobezoar in 8-year-old girl. It was not extracted endoscopically, because it was huge and passed into the duodenum. Attempts at dissolving the bezoar with enzymes (papain) or meat tenderizers have no been efficacious. The abdomen was explored through a supraumblical median incision, an approximately $15 \times 3 \mathrm{~cm}$ trichobezoar in diameter was identified in $50 \mathrm{~cm}$ distance from ileocecal segment, and was removed. In addition, ischemic and rupture $10 \mathrm{~cm}$ jejunal segment was repaired. These two rupture segments were repaired using Heineke Mikulicz procedure.

Keywords: Trichobezoar, abdominal mass, intestinal obstruction, rapunzel syndrome.

\section{GíRiş}

Bezoarlar, insan dokularından köken alan sert cisimler ya da sindirim sisteminde biriken sebze lifleridir. İnsanlarda görülen bezoarla ilgili ilk referans, 1779 'da mide perforasyonu ve peritonitis nedeniyle ölen bir hastanın otopsisi sonrasında bildirilmiştir $(1,2)$. İnsanlarda en sık görülen bezoar, saçlardan kaynaklanan trikobezoardır. Bununla beraber bezoarlar aynı zamanda, sebze, meyve lifleri (fitobezoar), süt kesiği (laktobezoar) ya da her hangi bir sindirilemeyen maddeden kaynaklanabilir. Diğer bezoarların aksine trikobezoarlar, sindirim sistemi motilitesindeki değişikliklerle ilgili değildir. Fakat altta yatan psikiyatrik rahatsızlıklarla ilgilidir ve en çok da hayatın ikinci dekadında adolesanlarda görülür. Trikobezoarların çoğu, geleneksel olarak saçı uzun olan kızlarda görülmüştür. Ayrıca kız kardeşlerinin saçını yutan bir erkek vaka da bildirilmiştir (3). Biz, 8 yaşındaki bir kız çocuğunda seyrek görülen dev bir trikobezoarı sunmaktayız.

Atıf yapmak için: Yurtçu M. Çok Sayıda Trikobezoar. Selcuk Med J 2019;35(3): 195-198

\section{OLGU}

8 yaşındaki bir kız çocuğu, saç yutma alışkanlığı olduğu gerekçesiyle hastanemize başvurdu. Hikayesinde kendi saçını yutma alışkanlığı, yemekten sonra ağrı ve kustuktan sonra rahatlama alışkanlığı olduğu öğrenildi. 8 ay önce endoskopik olarak hastanın midesindeki trikobezoar çıkarıldı. Hastanın fizik muayenesinde; abdominal distansiyon ve jejunal segmentin tümüyle obstrüksiyonuna bağlı safralı nazogastrik drenaj gözlendi. Karın muayenesinde sertlik ve yükselebilen kitlenin epigastrik bölgeden sağ üst kadrana uzandığı tespit edildi. Hastada barsak hareketleri artmıştı, diğer fizik muayene bulguları normaldi. Laboratuar tetkiklerinde konsantre idrar ve piyüri tespit edildi. Taze kan sayımı, pankreas enzimleri gibi biyokimyasal tetkikler normaldi. Üst gastrointestinal sistem çalışması ve endoskopik muayenede trikobezoar kolay bir şekilde teşhis edildi. Endoskopide, ince barsağa kadar uzadığına inanılan ve midede bulunan benekli maddeler görüldü. Fakat 


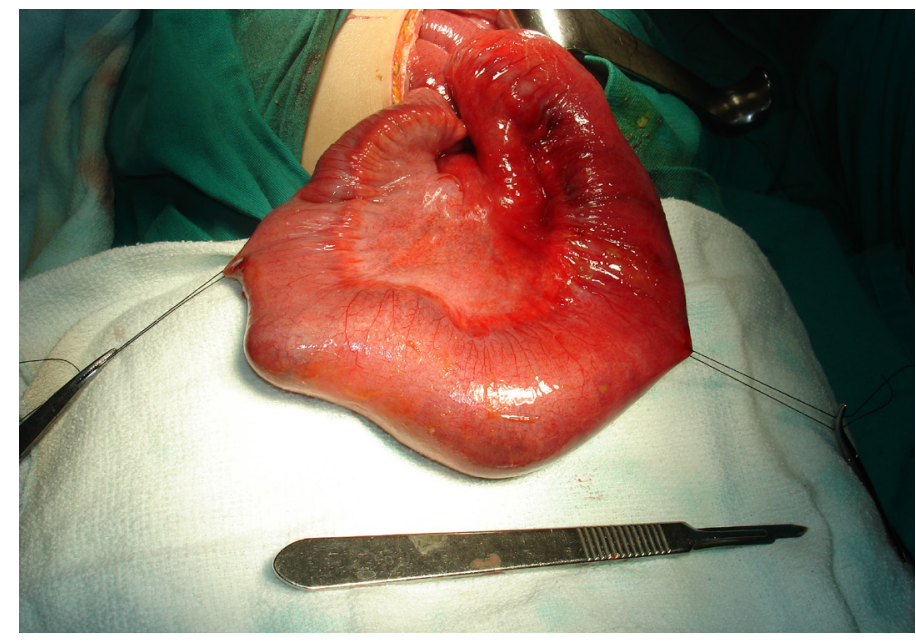

Şekil 1. İnce barsağa uzanan ve barsak şeklini alan dev bir trikobezoarın barsak içindeki peroperatif görünümü.

bu dev bezoar, endoskopik olarak çıkarılamadı. Çünkü oldukça büyük ve duodenuma geçmişti. Papain enzimi ile bezoarın eritilmesi ve yumuşatıcıların kullanılması etkili olmadı. Supraumblikal median kesi aracılığı ile karın içi eksplore edildi. Daha sonra, yaklaşık $15 X 3 \mathrm{~cm}$ ebadında trikobezoar; ileoçekal segmentin $50 \mathrm{~cm}$ proksimalinde tespit edildi (Şekil 1, 2) ve $5 \mathrm{~cm}$ 'lik longitudinal barsak kesisi ile çıkarıldı

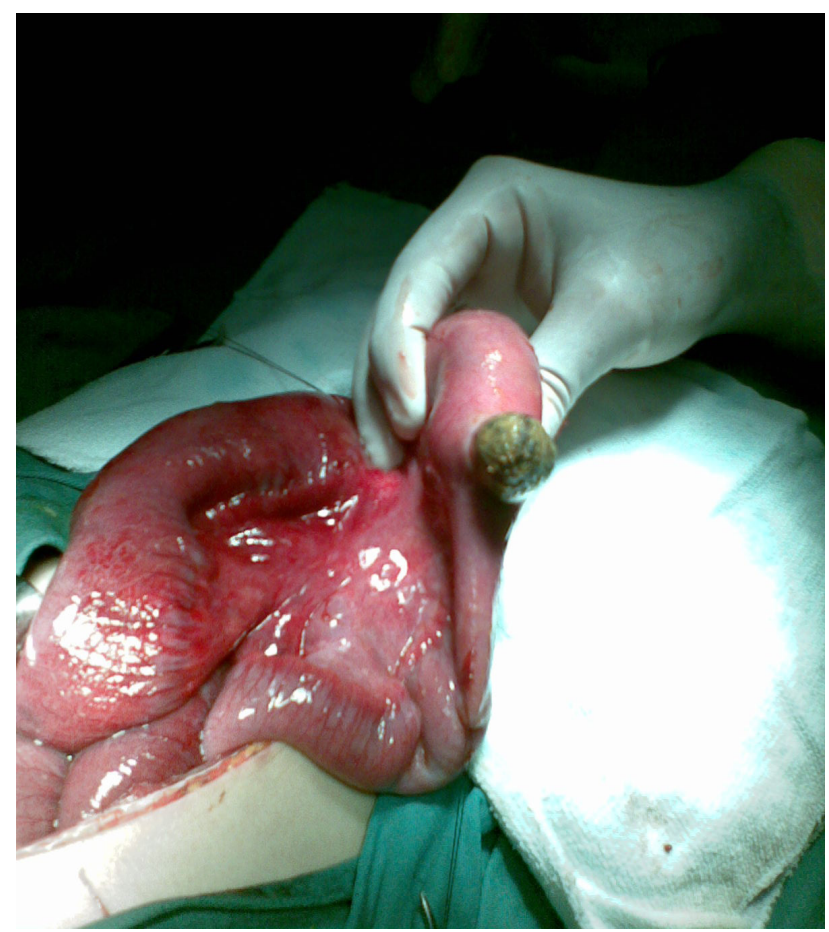

Şekil 2. İnce barsağa uzanan ve barsak şeklini alan dev bir trikobezoarın barsaktan çıkarıışının görünümü.

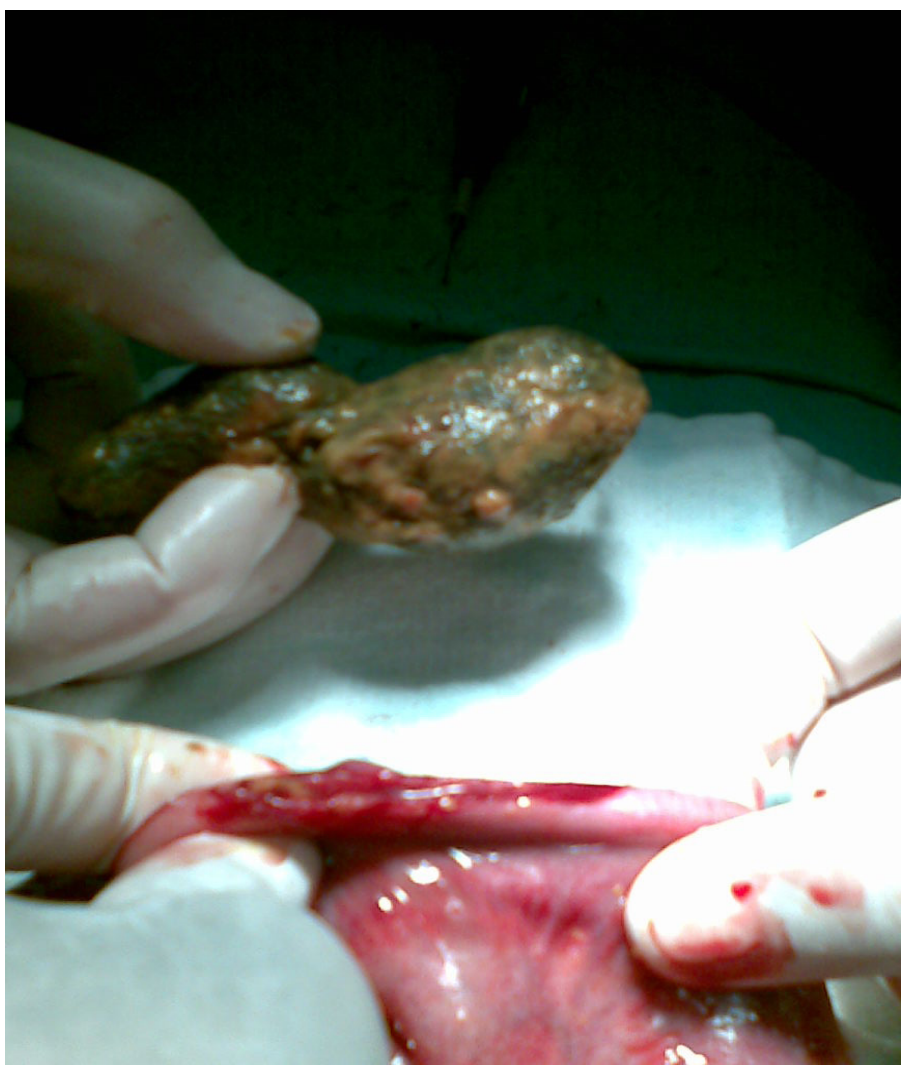

Şekil 3. İnce barsağa uzanan ve barsak şeklini alan dev bir trikobezoarın, cerrahi yolla anblok olarak çıkarılmış görünümü.

(Şekil 3). Ek olarak, Treitz Ligamenti'ne $10 \mathrm{~cm}$ mesafede olan ve distandü barsak basıncının neden olduğu $10 \mathrm{~cm}$ 'lik iskemik ve rüptüre jejunal segment onarıldı. Bu iki rüptüre segment; çift planda 3/0 ipekle tek tek sütürlerle, Heineke Mikulicz prosedürü uygulanarak onarıldı. Karın içine penröz dren yerleştirildikten sonra, karın duvarı bilinen şekilde kapatıldı. Enfeksiyon profilaksisi için parenteral olarak imipenem, aminoglikozid ve ornidazol verildi.

Tekrarlayan sorgulamalarda, kızın annesi trikofaji hikayesinden söz etti. Fizik muayenede alopesi gözlenmedi. Hasta yüz yüze sorgulamada, saç yemeyi sevdiğini kabul etti. Hastamız, operasyondan 10 gün sonra iyileşerek taburcu edildi. Nüksü önlemek için hasta, davranış düzenlenmesi amacıyla psikiatrik takibe alındı.

\section{TARTIŞMA}

Bezoarlar, sindirim sisteminde ve özellikle midedeki yabancı maddelerin oluşturduğu cisimlerdir. Saç veya saç benzeriliflerden oluşan bezoarlar, trikobezoar adını alırlar. Trikobezoarlı pek çok hastanın, kendi saçını 
çekme (trikotillomania) ve saç yeme (trikofaji)yi içeren psikolojik problemleri vardır. Trikofajili insanların, \% 1 'inde trikobezoar geliştiği tahmin edilmektedir $(4,5)$. Trikobezoarlar, kaygan yapılarından dolayı peristaltik dalgalarla mideye geçer; gastrik mukoza katlantıları içinde birikirler. Saç yığınları daha fazla biriktiğinde, peristaltizm ile bir top haline gelirler. Bu saç yumağı, mideyi terk edemeyecek kadar büyük olunca; gastrik atoni ortaya çıkabilir.

Rapunzel sendrom, trikobezoarın seyrek bir şeklidir, literatürde bunu tanımlamak için çeşitli kriterler kullanıldı. Bazılarına göre trikobezoar, ileoçekal valve kadar uzanan kuyruklu gastrik yapılardır $(1,6)$. Bazıları da jejunumun üst taraflarına kadar uzayabilen basit trikobezoar olarak tanımlar. Bazıları ise onu, intestinal obstrüksiyona neden olan her hangi bir boyuttaki bezoar olarak tanımlar (1). Bir bezoardan şüphe edildiğinde, trikotilomania ve bazı cisimlerin yutulması araştııılmalıdır. Fizik muayenede ağır ağız kokusu ve alopesi yaması önemli ip uçları verir. Görüntüleme yöntemlerinde, bezoarlı bir kitle ya da dolma defekti olarak görülebilir. Tanıda altın standart, üst sindirim sisteminin endoskopisidir. Direkt grafilere ek olarak yapılan endoskopi, tanı ve tedavide de yardımcı olur.

Sertlik, boyut ve yerleşimine bağlı olarak, bezoarın çıkarılması endoskopik ya da cerrahi yol ile mümkün olabilir. Fitobezoar ve laktobezoarların hacmi uygun boyutta olduğu müddetçe endoskopik olarak çıkarılmaları mümkündür; ancak özellikle büyük trikobezoarların endoskopik olarak çıkarılmaları oldukça zordur (7).

Büyük boyutta bir bezoar olduğunda, Rapunzel sendromunda çok büyük ya da solit bir bezoarın neden olduğu perforasyon ya da kanama olduğunda; cerrahi endikasyon vardır (4). Cerrahi tedavi, gastrotomi ya da enterotomi ile gerçekleştirilir. Bilindiği gibi üst orta hattan laparatomi aracılığı ile yapılan gastrotomi ile gastrik trikobezoar çıkarılır. Minimal invazif cerrahi yaygınlaştığından beri, cerrahlar artık küçük ve orta boyuttaki bezoarlar için laparoskopik teknikleri kullanmaktadırlar $(1,8,9)$. Ekstrakorporeal şok dalga litotripsi, intragastrik enzim (pankreatik lipaz, selülaz) uygulaması ve ilaç uygulamaları (metoklopromid, asetil sistein) ile değişik sonuçlar alınmaktadır (8). Bezoarların çıkarılmasından sonra sadece bir kaç nüks vaka bildirilmiştir $(2,9,10)$. Rekürrensleri önlemek için, uzun dönem psikiyatrik takip önerilir.

Çocuklarda trikobezoarlarla ilgili olgu sunumları az sayıdadır ve bunlar erken çocukluk dönemindeki istismarlar (11), psikiatrik bozukluklar $(11,12)$, mental retardasyon $(13,14)$, ya da yoksunluk sendromları ile ilgilidir (1,15). Ebeveynlerle konsültasyon, tedavinin önemli bir parçası olup; nüksü önlemek için çok önemlidir. Davranış tedavisi uygun şekilde yapılırsa, hastanın uzun dönemdeki prognozu mükemmeldir. Ayrıca psikolojik ve psikiyatrik takip de önemlidir.

Sonuç olarak, genç yetişkinlerdeki yumuşak olmayan abdominal kitle ve karın ağrısının ayırıcı teşhisinde trikobezoar da düşünülmelidir. Ayrıca pika hikayesi her zaman sorgulanmalıdır. Küçük bezoarlar; endoskopik yöntem, gastrik lavaj, enzimatik tedavi ya da bunların kombinasyonu ile çıkarılabilir. Daha büyük bezoarlar ise cerrahi olarak çıkarılmaya intiyaç gösterebilir. Bu hastaların çoğunda duygusal problemler, aile içi huzursuzluk, inmal edilme hikayesi ya da mental retardasyon ile birlikte psikolojik patolojiler mevcuttur. Psikiyatristlerle konsültasyon, nüksleri önlemek için tedavinin önemli bir parçasıdır. Karın ağrısı, kusma ve abdominal kitle hikayesi olan genç kızlarda, ayırıcı tanıda büyük trikobezoarlar düşünülmelidir.

Çıkar Çatışması: Çalışmada herhangi bir çıkar çatışması yoktur.

Finansal Çıkar Çatışması: Çalışmada herhangi bir finansal çıkar çatışması yoktur.

Yazışma Adresi: Müslim Yurtçu, Necmettin Erbakan Üniversitesi Meram Tıp Fakültesi, Çocuk Cerrahisi Anabilim Dalı, Konya, Türkiye.

Telefon: 05462518935

E-posta: myurtcu@konya.edu.tr

\section{KAYNAKLAR}

1. Naik S, Gupta V, Rangole A, et al. Rapunzel syndrome reviewed and redefined. Dig Surg 2007;24:157-61.

2. Vaughan ED Jr, Sawyers JL, Scott HW Jr. The Rapunzel syndrome. An unusual complication of intestinal bezoar. Surgery 1968;63:339-43.

3. Hirugade ST, Talpallikar MC, Deshpande AV, et al. Rapunzel syndrome with a long tail. Indian J Pediatr 2001;68:895-6.

4. Phillips MR, Zaheer S, Drugas GT. Gastric trichobezoar: Case report and literature review. Mayo Clin Proc 1998;73:653-6.

5. Irving PM, Kadirkamanathan SS, Priston AV, et al. Education and imaging. Gastrointestinal rapunzel syndrome. J Gastroenterol Hepatol 2007;22:2361.

6. Kaspar A, Deeg KH, Schmidt K, et al. Rapunzel syndrome, an rare form of intestinal trichobezoars. Klin Pediatr 1992;211:420-2.

7. Wang YG, Seitz U, Li ZL, et al. Endoscopic management of huge bezoars. Endoscopy 1998;30:371-4.

8. Groenewald CB, Smoot RL, Farley DR, et al. A football-sized gastric mass in a healthy teen. Contemp Surg 2006;62:5314.

9. Eryilmaz R, Sahin M, Alimoğlu O, et al. A case of Rapunzel syndrome. Ulus Travma Acil Cerrahi Derg 2004;10:260-3.

10. Memon SA, Mandhan P, QureshiZN, etal. Recurrent Rapunzel syndrome-a case report. Med Sci Monit 2003;9:CS92-4. 
11. Gockel I, Gaedertz C, Hain HJ, et al. The Rapunzel syndrome: Rare manifestation of a trichobezoar of the upper gastrointestinal tract. Chinurg 2003;74:753-6.

12. Sharma NL, Sharma RC, Mahajan VK, et al. Trichotillomania and trichophagia leading to trichobezoar. J Dermatol 2000;27:24-6.

13. Schulte-Markwort $M$, Bachmann $M$, Riedesser $P$. Trichobezoar in a 16-year old girl. Case report and review of the literature. Nervenarzt 2000;71:584-7.
14. Ramadan N, Pandya NA, Bhaduri B, et al. A Rapunzel with a difference. Arch Dis Child 2003;88:2604.

15. Duncan ND, Aitken R, Venugopal S, et al. The Rapunzel syndrome. Report of a case and review of the literature. West Indian Med J 1994;43:63-5. 